OPEN ACCESS

Edited by:

Petr Kralik,

Veterinary Research Institute,

Czech Republic

Reviewed by:

Dimitris Tsaltas,

Cyprus University of Technology,

Cyprus

Anu Susan Charles,

Louisiana State University, USA

${ }^{*}$ Correspondence:

David Rodríguez-Lázaro

rodlazda@gmail.com;

drlazaro@ubu.es

${ }^{\dagger}$ These authors have contributed equally to this work.

Specialty section: This article was submitted to

Food Microbiology,

a section of the journal

Frontiers in Microbiology

Received: 14 October 2016 Accepted: 30 November 2016 Published: 15 December 2016

Citation:

Quijada NM, Fongaro G, Barardi CRM, Hernández M and Rodríguez-Lázaro D (2016) Propidium Monoazide Integrated with qPCR Enables the Detection and Enumeration of Infectious Enteric RNA and DNA Viruses in Clam

and Fermented Sausages.

Front. Microbiol. 7:2008.

doi: 10.3389/fmicb.2016.02008

\section{Propidium Monoazide Integrated with qPCR Enables the Detection and Enumeration of Infectious Enteric RNA and DNA Viruses in Clam and Fermented Sausages}

\author{
Narciso M. Quijada ${ }^{1 \dagger}$, Gislaine Fongaro ${ }^{2 \dagger}$, Célia R. M. Barardi ${ }^{2}$, Marta Hernández ${ }^{1,3}$ and \\ David Rodríguez-Lázaro **
}

'Laboratory of Molecular Biology and Microbiology, Instituto Tecnológico Agrario de Castilla y León, Valladolid, Spain, ${ }^{2}$ Laboratório de Virologia Aplicada, Departamento de Microbiologia, Imunologia e Parasitologia, Universidade Federal de Santa Catarina, Florianópolis, Brazil, ${ }^{3}$ Departamento de Ingeniería Agrícola y Forestal, Tecnología de los Alimentos, Escuela Técnica Superior de Ingenierías Agrarias, Universidad de Valladolid, Palencia, Spain, ${ }^{4}$ Division of Microbiology, Department of Biotechnology and Food Science, Universidad de Burgos, Burgos, Spain

The increase of foodborne viral outbreaks highlights the need for a rapid and sensitive method for the prediction of viral infectivity in food samples. This study assesses the use of propidium monoazide (PMA) coupled with real-time PCR methods (RT-qPCR or qPCR for RNA or DNA viruses, respectively) in the determination of viral infectivity in complex animal-related food matrices. Clam and Spanish fermented sausage ("chorizo") samples were spiked with infectious and heat-inactivated human adenovirus-2 (HAdV-2) and mengovirus $\left(\mathrm{VMC}_{0}\right)$. PMA-qPCR/RT-qPCR discriminated infective virus particles, with significant reductions (>2.7 $\log _{10}$ or $99.7 \%$ ). Additionally, infectious HAdV-2 and $\mathrm{VMC}_{0}$ were quantified by plaque assay (in plaque forming units, PFU), and compared with those in virus genomes copies (GCs) quantified by PMA-qPCR/RT-qPCR. A consistent correlation $\left(R^{2}>0.92\right)$ was showed between PFU and GCs along serial 10-fold dilutions in both DNA and RNA virus and in both food matrices. This study shows the use of PMA coupled to qPCR/RT-qPCR as a promising alternative for prediction of viral infectivity in food samples in comparison to more expensive and time-consuming methods and for those viruses that are not able to grow under available cell culture techniques.

Keywords: enteric viruses, infectivity prediction, PMA-PCR, clam, fermented sausage

\section{INTRODUCTION}

Food and food related environments are a major source of viral transmission to humans (Koopmans et al., 2002; Rodríguez-Lázaro et al., 2012). Several viruses, particularly noroviruses (NoV), hepatitis A virus (HAV), and hepatitis E viruses (HEV) are related to foodborne outbreaks and their incidence has increased considerably during the last years becoming a serious and widespread global public health threat (Rodríguez-Lázaro et al., 2009). Human NoV are responsible of more than five millions of gastroenteritis illnesses in USA annually, which represents more than $50 \%$ of the infectious cases (Scallan et al., 2011). These agents are recognized as major causes of foodborne illnesses, which can vary from gastroenteritis to hepatitis, paralysis or aseptic meningitis (Bosch et al., 2011). 
Food-borne viruses can be present in different food matrices (Croci et al., 2008; Greening and Hewitt, 2008), although minimally processed food products, such as shellfish or fresh produced, are the most commonly related with food-borne viral outbreaks (Pintó et al., 2009). Shellfish have been considered as a major source of food-borne viruses due to their filter-feeding mechanism that can concentrate virus from polluted waters (Carter, 2005). Pork meat products are also a significant route of zoonotic transmission, as enteric viruses can infect humans from the consumption of contaminated raw or undercooked pork meat (Martínez-Martínez et al., 2011).

The increase in foodborne viral outbreaks highlights the need for rapid, sensitive, and specific methods for food safety monitoring, enabling the detection and quantification of viable foodborne viruses (Elizaquível et al., 2014). Traditional cell culture methods are laborious and time consuming, and many of the major enteric viruses cannot be or are difficult to adapt to conventional in vitro cell lines. The use of nucleic acid-based methods such as polymerase chain reaction (PCR) and real-time PCR ( $\mathrm{qPCR}$ or RT-qPCR for DNA or RNA viruses, respectively) has become an alternative (Rodríguez-Lázaro et al., 2007). Nevertheless PCR-related methods are not able to discriminate between infectious and non-infectious viral particles which can drive to an overestimation of the target viruses with potential implication in public health and consequently positive results should be taken with precautions (Choi and Jiang, 2005; Hamza et al., 2011).

Coupling propidium monoazide (PMA) with PCR, qPCR or RT-qPCR appears as a promising alternative to overcome this issue. PMA is a nucleic acid intercalating dye that only crosses damaged lipid membrane barriers. Once inside, PMA binds and covalently crosslinks DNA/RNA after exposure to strong visible light, interfering DNA amplification. The rest of genomes, with the entire lipid membrane barrier, are not affected by PMA and can be amplified with PCR (Nogva et al., 2003; Nocker et al., 2006; Fittipaldi et al., 2012).

This study assesses the use of PMA coupled to qPCR or RT-qPCR in order to distinguish between infectious and noninfectious viruses in two different food matrices: clam and Spanish fermented pork sausage ("chorizo"). "Chorizo" is the most popular Spanish dry fermented sausage with more than 20 varieties described. The main ingredients are lean pork, pork fat, salt and spices (garlic, Spanish paprika, etc.), but the composition may vary depending on its geographical region. The raw sausage is then smoked or not and stuffed into natural or artificial casings and ripened at low temperature $\left(12-24^{\circ} \mathrm{C}\right.$ ) and relatively high moisture (from 65 to 96\%; González and Díez, 2002; De las Rivas et al., 2008). When the ripening process is over, "chorizo" is consumed raw. We artificially seeded the food samples with adenovirus-2 (HAdV2 ) and mengovirus $\left(\mathrm{vMC}_{0}\right)$ as virus surrogates. These viruses were chosen as they represent DNA and RNA enteric viruses, respectively: mengovirus $\left(\mathrm{vMC}_{0}\right)$ has been used as a surrogate for several non-culturable enteric RNA viruses such as HAV and HEV, and adenoviruses have been used as bioindicators in different studies (De Motes et al., 2004; Hundesa et al., 2006).

\section{MATERIALS AND METHODS}

\section{Enteric Virus Production and Quantification}

Mengovirus ( $\mathrm{vMC}_{0}$ ) and Human adenovirus type 2 (HAdV-2) stocks were cultured in HeLa and A549 cells lines, respectively. Infected cells were freeze-thaw during three cycles after 3-5 days post-infection and cell debris was discarded after centrifugation at $600 \times g$ for $30 \mathrm{~min}$. Infectious viruses were quantified by plaque assay as previously described by Borden et al. (1970) and Cromeans et al. (2008). Plaques were counted after incubation at $37^{\circ} \mathrm{C}$ during $5-7$ days.

\section{Food Samples}

Clam and "chorizo" samples were purchased from a local supermarket. For viral analysis, $20 \mathrm{~g}$ of each food matrix was prepared using either a pool of clam's digestive glands in duplicate or a pool of six parts from three different "chorizos," for clam and "chorizo" samples, respectively. The samples were then clarified and concentrated using a glycine buffer method coupled with polyethylene glycol precipitation, and the viral particles were eluted using a glycine buffer $(\mathrm{pH} 9.5)$ and further concentrated with PEG 6000 precipitation (Fongaro et al., 2014). After centrifugation, supernatant was discarded and the resulting pellet was suspended in $2.0 \mathrm{~mL}$ of $0.1 \mathrm{M}$ phosphate buffer $(\mathrm{pH}$ 7.2; from now on called "processed sample").

\section{Artificial Contamination of Food Samples}

Processed clam and "chorizo" samples were artificially contaminated with $\mathrm{vMC}_{0} 6 \times 10^{5}$ plaque forming unity per $\mathrm{mL}\left(\mathrm{PFU} \mathrm{mL}{ }^{-1}\right)$ and HAdV-2 $8 \times 10^{7} \mathrm{PFU} \mathrm{mL}^{-1}$. Clam and "chorizo" processed samples were previously treated with $10 \mathrm{U} / \mathrm{mL}$ penicillin, $10 \mu \mathrm{g} / \mathrm{mL}$ streptomycin and $0.025 \mu \mathrm{g} / \mathrm{mL}$ amphotericin B and inoculated with the virus suspension $(0.25 \mathrm{~mL})$ at a non-cytotoxic dilution, in triplicate, in the respective cells for plaque assay. Plaques were counted after incubation at $37^{\circ} \mathrm{C}$ during $5-7$ days.

For spiked samples, the following scenarios were performed: concentrated food samples spiked with viral fluids containing infectious HAdV-2 and $\mathrm{vMC}_{0}$ viruses (i) with and (ii) without addition of PMA and concentrated food samples spiked with viral fluids containing thermally inactivated HAdV-2 and $\mathrm{vMC}_{0}$ viruses (viral suspensions in a water bath at $95^{\circ} \mathrm{C}$ for $10 \mathrm{~min}$; iii) with and (iv) without addition of PMA.

\section{PMA Treatment and Nucleic Acids Extraction}

One-hundred microliters of processed samples were mixed with PMA (50 $\mu \mathrm{M}$ of final concentration -Fongaro et al., 2016; SigmaAldrich), and samples were incubated in a dark room at $25^{\circ} \mathrm{C}$ for $10 \mathrm{~min}$ under rotation at $200 \mathrm{rpm}$, to allow reagent penetration. Treated samples were then exposed to $40 \mathrm{~W}$ LED light at $460 \mathrm{~nm}$ wavelength for $15 \mathrm{~min}$ at room temperature using a photoactivation system [Led-Active Blue (PhAST Blue, Geniul)]. After the photo-activation, a rinse step was performed and nucleic acids were extracted using the DNA and RNA QIAamp Viral Mini 
Kit (Qiagen, Hilden, Germany), according to the manufacturer's instructions.

\section{qPCR and RT-qPCR Assays}

qPCR (DNA viruses) or RT-qPCR (RNA viruses) were performed for viral detection using a LightCycler 2.0 instrument (Roche Diagnostics) with the conditions previously described for HAdV2 (Hernroth et al., 2002) and $\mathrm{vMC}_{0}$ (Costafreda et al., 2006), including an internal amplification control (Diez-Valcarce et al., 2012). Each sample was analyzed in duplicate. For each PCR run, four serial standard dilutions were used in triplicate for each assay, and the genome copies (GC) were calculated. Ultrapure water was used as the non-template control for each assay.

\section{Statistical Analyses}

Results were evaluated statistically using one-way analysis of variance (ANOVA) to evaluate differences between the groups ( $95 \%$ confidence level), followed by Bonferroni's Multiple Comparison Test to evaluate the differences in greater depth. Pearson test was applied for correlation analysis. The mean equivalence of PFU units (by plaque assay) versus GC (by PMA-qPCR/RT-qPCR) was tested by Linear Regression test. All statistical analyses were performed in GraphPad Prism 5.0 (USA) and the critical $p$-value for the test was set at $<0.05$.

\section{RESULTS}

\section{Determination of Virus Surrogates Infectivity in Food Samples Using PMA}

In order to assess the interference produced by PMA, food samples were firstly spiked with infectious virus particles and then treated (or not) with PMA prior to real-time PCR (qPCR for HAdV-2 and RT-qPCR for $\mathrm{vMC}_{0}$ ). No statistically significant $(p>0.05)$ differences were observed between PMA-treated and PMA-non-treated samples spiked with identical amounts of infective viruses. Differences were below 1 log unit regardless of the type of food sample assayed: $0.42 \pm 0.14$ and $0.44 \pm 0.17$ for HAdV-2 and $0.31 \pm 0.18$ and $0.33 \pm 0.14$ for $\mathrm{vMC}_{0}$ in clam and "chorizo" samples, respectively.
Furthermore, clam and "chorizo" samples were spiked with decreasing amounts of thermally inactivated viral particles $\left(\mathrm{HAdV}-2\right.$ and $\mathrm{vMC}_{0}$ ) that were submitted (or not) to a treatment with PMA prior to real-time PCR (qPCR for HAdV-2 and RT$\mathrm{qPCR} \mathrm{vMC}_{0}$ ) and the ability of the method for distinguishing between infectious and inactivated viruses was evaluated. Results are shown in Figure 1. Significant reductions of virus genome equivalents (GCs; $p<0.05$ ) were observed in samples treated with PMA prior to real-time PCR, where the mean values were $3.6 \pm 0.5$ ( $\log _{10}$ units) and $3.2 \pm 0.6$ for HAdV-2 and $2.7 \pm 0.4$ and $3.3 \pm 0.1$ for $\mathrm{vMc}_{0}$ in clam and "chorizo" samples, respectively (Figure 2). It represents a mean PCR derived signal reduction of 99.96 and $99.92 \%$ for HAdV-2 and 99.70 and $99.93 \%$ for $\mathrm{vMc}_{0}$ in clam and "chorizo" samples, respectively.

\section{Equivalence of PFU vs. GC}

Infectious HAdV-2 and $\mathrm{vMC}_{0}$ were quantified by plaque assay (PFUs) and the results were compared to those obtained in virus GCs quantified by PMA-qPCR/RT-qPCR. The mean equivalences were close to $3 \log _{10}$ units regardless the type of food samples assayed: $2.8 \pm 0.3$ ( $\log _{10}$ units) and $2.8 \pm 0.4$ for HAdV-2 and $2.6 \pm 0.1$ and $2.7 \pm 0.4$ for $\mathrm{vMC}_{0}$ in clam and "chorizo" samples, respectively. These equivalences were calculated and confirmed along 10-fold dilutions of PFU units by statistical testing [Linear Regression, GraphPad Prism version 5.0 (USA)]. The $R^{2}$ values obtained ranged from 0.92 to 0.99 , demonstrating an excellent linearity regardless the dilution of the PFU units and food samples tested (Figure 3).

\section{DISCUSSION}

Food-borne diseases are one of the major priorities of the World Health Organization (WHO) as they are widespread and their incidence has increased during the last years (Elizaquível et al., 2014). Enteric viruses, such as human NoV, hepatitis $\mathrm{A}$ and $\mathrm{E}$ viruses, enteroviruses, rotaviruses, or astroviruses are present in food products and those that are consumed raw or undercooked are commonly related with viral foodborne outbreaks. These products include fruits, vegetables, shellfish (oysters, clams and mussels) and pig-derived products such as

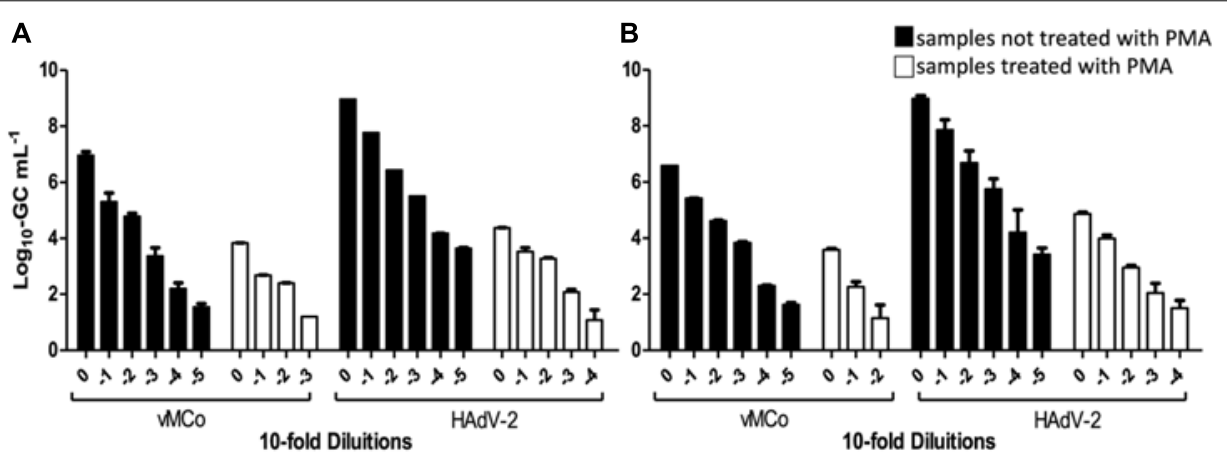

FIGURE 1 | Detection of thermally inactivated vMCo and HAdV-2 with and without PMA treatment in (A) clam and (B) "chorizo" samples. White and black bars represent whether the samples were treated or not with PMA, respectively. 


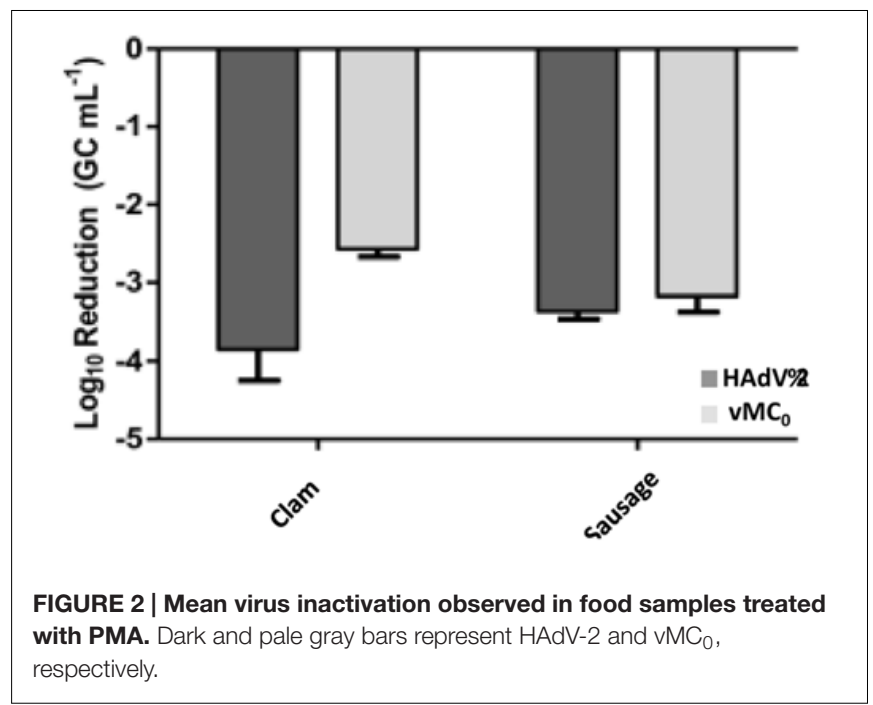

fermented meat products consumed raw (Le Guyader et al., 2006; Parshionikar et al., 2010; Sanchez et al., 2012). Hence, the development of methods that allow the rapid and sensitive detection and quantification of enteric viruses in food products are of great value to the food industry (Perelle et al., 2007). Detection of enteric viruses based only in genome detection does not provide an accurate analysis of viral load and cannot determine the infectivity potential. Viral infectivity studies include cell culture methods in order to demonstrate cytopathic effect. Such experiments can be laborious, and many viruses do not produce cytopathic effects (Rodríguez et al., 2009). Several viability staining-PCR strategies have been used in detection foodborne pathogens using different dyes such as PMA or ethidium monoazide (EMA). These dyes penetrate only in capside-compromised viruses. However, the applicability of this viability-PCR strategy must be tested for each type of food matrix due to composition complexity of foods, and the use of PMA as dye for sample pretreatment previous to the qPCR has been described as more suitable (Elizaquível et al., 2014).
Although coupling PMA with qPCR or RT-qPCR has been successfully applied to discriminate infectious and inactivated virus particles from viral suspension, river water, vegetables, swine raw manure, swine effluent from anaerobic biodigesters and biofertilized soil (Parshionikar et al., 2010; Sanchez et al., 2012; Coudray-Meunier et al., 2013; Moreno et al., 2015; Fongaro et al., 2016) little is known about the applicability of this technique in complex animal origin foods. In this study we chose two different food matrices: clam and Spanish fermented sausage ("chorizo"). Clam is a widely consumed product and they are known to concentrate virus from polluted water due to its filtering-feeding mechanism (Carter, 2005). "Chorizo" is a pork sausage made of combination of pork lean and fat with several spices (including Spanish paprika) and it is consumed raw after ripening.

The results of this study show that coupling PMA with qPCR or RT-qPCR successfully discriminates among infective and inactivated HAdV-2 and $\mathrm{vMC}_{0}$ in clam and "chorizo" samples. This is the first study that assesses the possible usage of PMA coupled with qPCR/RT-qPCR in the determination of the infectivity of viral particles on food samples from animal origin. PMA activity was not inhibited by the processing of the two complex food matrices tested and did not interfere significantly in the genome quantification by qPCR/RT-qPCR. The hit of this study is the successful application of the method over complex food matrices, highlighting the use of PMA coupled with qPCR/RT-qPCR as a promising alternative for enteric virus determination in food safety studies. Noteworthy, a consistent correlation $\left(R^{2}>0.92\right)$ was observed along serial 10 -fold dilutions in both DNA and RNA virus and in both clam and "chorizo" samples, even though a complete reduction of the signal for thermally inactivated virus particles was not obtained.

\section{CONCLUSION}

The combination of PMA with $\mathrm{qPCR} / \mathrm{RT}-\mathrm{qPCR}$ is a promising alternative for enteric virus investigation in food safety, particularly regarding to non-cultivable viruses, that allows the
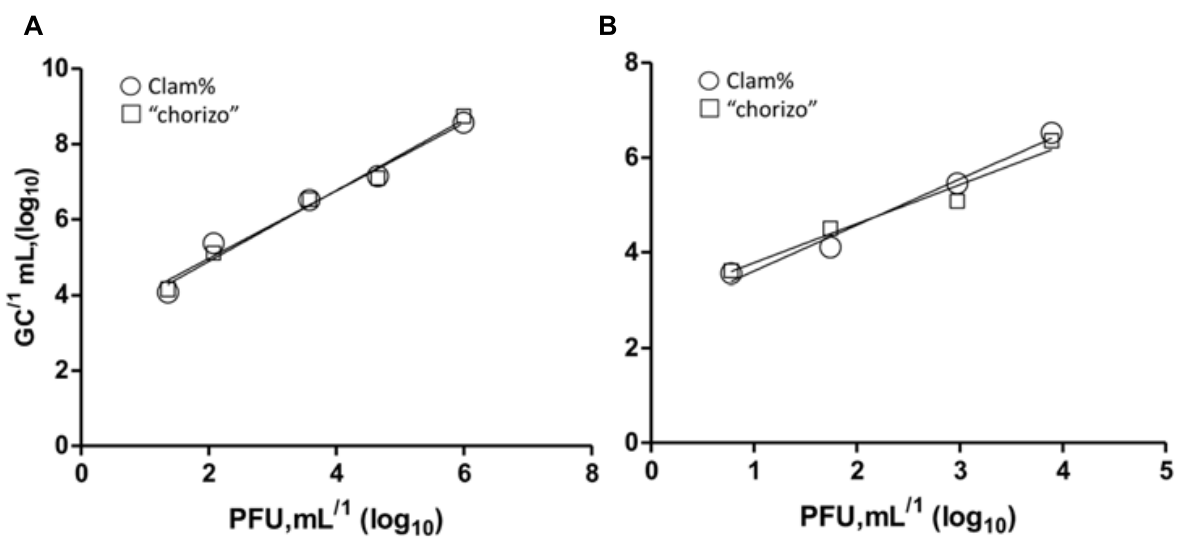

FIGURE 3 | Mean equivalences correlation of PFU and GCs in 10-fold dilutions of HAdV-2 (A) and VMCO (B). Balls and squares represent clam and "chorizo" samples, respectively. The $R^{2}$ values were 0.92 and 0.99 for HAdV-2 and 0.96 and 0.96 for vMC in clam and "chorizo" samples, respectively. 
discrimination between damaged and undamaged virus particles in animal-related food products.

\section{AUTHOR CONTRIBUTIONS}

NQ and GF performed the experiments and contributed in the preparation of the first draft of the manuscript. $\mathrm{MH}$ collaborated in the definition of the experimental part and contributed in the revision of the experiments and preparation of the final version of the manuscript. CB contributed in the preparation of the final

\section{REFERENCES}

Borden, E. C., Gary, G. W., and Murphy, F. A. (1970). Comparison of agar and agarose preparations for mengovirus plaque formation. Appl. Environ. Microbiol. 20, 289-291.

Bosch, A., Sánchez, G., Abbaszadegan, M., Carducci, A., Guix, S., Le Guyader, F. S., et al. (2011). Analytical methods for virus detection in water and food. Food Anal. Methods 4, 4-12. doi: 10.1007/s12161-010-9161-5

Carter, M. J. (2005). Enterically infecting viruses: pathogenicity, transmission and significance for food and waterborne infection. J. Appl. Microbiol. 98, 1354-1380. doi: 10.1111/j.1365-2672.2005.02635.x

Choi, S., and Jiang, S. C. (2005). Real-time PCR quantification of human adenoviruses in urban rivers indicates genome prevalence but low infectivity real-time PCR quantification of human adenoviruses in urban rivers indicates genome prevalence but low infectivity. Appl. Environ. Microbiol. 71, 7426-7433. doi: 10.1128/AEM.71.11.7426

Costafreda, M. I., Bosch, A., and Pintó, R. M. (2006). Development, evaluation, and standardization of a real-time TaqMan reverse transcription-PCR assay for quantification of hepatitis A virus in clinical and shellfish samples. Appl. Environ. Microbiol. 72, 3846-3855. doi: 10.1128/AEM.02660-05

Coudray-Meunier, C., Fraisse, A., Martin-Latil, S., Guillier, L., and Perelle, S. (2013). Discrimination of infectious hepatitis A virus and rotavirus by combining dyes and surfactants with RT-qPCR. BMC Microbiol. 13:216. doi: 10.1186/1471-2180-13-216

Croci, L., Dubois, E., Cook, N., De Medici, D., Schultz, A. C., China, B., et al. (2008). Current Methods for extraction and concentration of enteric viruses from fresh fruit and vegetables: towards international standards. Food Anal. Methods 1, 73-84. doi: 10.1007/s12161-008-9025-4

Cromeans, T. L., Lu, X. Y., Erdman, D. D., Humphrey, C. D., and Hill, V. R. (2008). Development of plaque assays for adenoviruses 40 and 41. J. Virol. Methods 151, 140-145. doi: 10.1016/j.jviromet.2008.03.007

De las Rivas, B., Ruiz-Capillas, C., Carrascosa, A. V., Curiel, J. A., JiménezColmenero, F., and Muñoz, R. (2008). Biogenic amine production by Grampositive bacteria isolated from Spanish dry-cured "chorizo" sausage treated with high pressure and kept in chilled storage. Meat Sci. 80, 272-277. doi: 10.1016/j.meatsci.2007.12.001

De Motes, C. M., Clemente-Casares, P., Hundesa, A., Martín, M., and Girones, R. (2004). Detection of bovine and porcine adenoviruses for tracing the source of fecal contamination. Appl. Environ. Microbiol. 70, 1448-1454. doi: 10.1128/ AEM.70.3.1448

Diez-Valcarce, M., Kokkinos, P., Söderberg, K., Bouwknegt, M., Willems, K., de Roda-Husman, A. M., et al. (2012). Occurrence of human enteric viruses in commercial mussels at retail level in three European countries. Food Environ. Virol. 4, 73-80. doi: 10.1007/s12560-012-9078-9

Elizaquível, P., Aznar, R., and Sánchez, G. (2014). Recent developments in the use of viability dyes and quantitative PCR in the food microbiology field. J. Appl. Microbiol. 116, 1-13. doi: 10.1111/jam.12365

Fittipaldi, M., Nocker, A., and Codony, F. (2012). Progress in understanding preferential detection of live cells using viability dyes in combination with DNA amplification. J. Microbiol. Methods 91, 276-289. doi: 10.1016/j.mimet.2012. 08.007

Fongaro, G., Hernández, M., García-González, M. C., Barardi, C. R. M., and Rodríguez-Lázaro, D. (2016). Propidium monoazide coupled with PCR predicts version of the manuscript, and DR-L defined the experimental approach, revised the results and led the preparation of the manuscript.

\section{FUNDING}

This study was financially supported by the RTA2014-00024C04-01 from the Spanish Ministry of Economy and Innovation and the Brazilian CNPq Project number 472804/2013-8, and by CAPES/PNPD and CAPES/PDSE.

infectivity of enteric viruses in swine manure and biofertilized soil. Food Environ. Virol. 8, 79-85. doi: 10.1007/s12560-015-9225-1

Fongaro, G., Viancelli, A., Magri, M. E., Elmahdy, E. M., Biesus, L. L., Kich, J. D., et al. (2014). Utility of specific biomarkers to assess safety of swine manure for biofertilizing purposes. Sci. Total Environ. 479-480, 277-283. doi: 10.1016/j. scitotenv.2014.02.004

González, B., and Díez, V. (2002). The effect of nitrite and starter culture on microbiological quality of "chorizo" - A Spanish dry cured sausage. Meat Sci. 60, 295-298. doi: 10.1016/S0309-1740(01)00137-1

Greening, G. E., and Hewitt, J. (2008). Norovirus detection in shellfish using a rapid, sensitive virus recovery and real-time RT-PCR detection protocol. Food Anal. Methods 1:109. doi: 10.1007/s12161-008-9018-3

Hamza, I. A., Jurzik, L., Überla, K., and Wilhelm, M. (2011). Methods to detect infectious human enteric viruses in environmental water samples. Int. J. Hyg. Environ. Health 214, 424-436. doi: 10.1016/j.ijheh.2011.07.014

Hernroth, B. E., Conden-Hansson, A. C., Rehnstan-Holm, A. S., Girones, R., and Allard, A. K. (2002). Environmental factors influencing human viral pathogens and their potential indicator organisms in the blue mussel, Mytilus edulis: the first Scandinavian report. Appl. Environ. Microbiol. 68, 4523-4533. doi: 10.1128/ AEM.68.9.4523-4533.2002

Hundesa, A., Maluquer De Motes, C., Bofill-Mas, S., Albinana-Gimenez, N., and Girones, R. (2006). Identification of human and animal adenoviruses and polyomaviruses for determination of sources of fecal contamination in the environment. Appl. Environ. Microbiol. 72, 7886-7893. doi: 10.1128/AEM. 01090-06

Koopmans, M., von Bonsdor, C., Vinje, J., de Medici, D., and Monroe, S. (2002). Foodborne viruses. FEMS Microbiol. Rev. 26, 187-205. doi: 10.1016/S01686445(02)00096-7

Le Guyader, F. S., Loisy, F., Atmar, R. L., Hutson, A. M., Estes, M. K., RuvoenClouet, N., et al. (2006). Norwalk virus-specific binding to oyster digestive tissues. Emerg. Infect. Dis 12, 931-936. doi: 10.3201/eid1206.051519

Martínez-Martínez, M., Diez-Valcarce, M., Cook, N., Hernández, M., and Rodríguez-Lázaro, D. (2011). Evaluation of extraction methods for efficient detection of enteric viruses in pork meat products. Food Anal. Methods 4, 13-22. doi: 10.1007/s12161-010-9165-1

Moreno, L., Aznar, R., and Sánchez, G. (2015). Application of viability PCR to discriminate the infectivity of hepatitis A virus in food samples. Int. J. Food Microbiol. 201, 1-6. doi: 10.1016/j.ijfoodmicro.2015.02.012

Nocker, A., Cheung, C. Y., and Camper, A. K. (2006). Comparison of propidium monoazide with ethidium monoazide for differentiation of live vs. dead bacteria by selective removal of DNA from dead cells. J. Microbiol. Methods 67, 310-320. doi: 10.1016/j.mimet.2006.04.015

Nogva, H. K., Dromtorp, S. M., Nissen, H., and Rudi, K. (2003). Ethidium monoazide for DNA-based differentiation of viable and dead bacteria by 5 'nuclease PCR. Biotechniques 34, 804-813.

Parshionikar, S., Laseke, I., and Fout, G. S. (2010). Use of propidium monoazide in reverse transcriptase PCR to distinguish between infectious and noninfectious enteric viruses in water samples. Appl. Environ. Microbiol. 76, 4318-4326. doi: 10.1128/AEM.02800-09

Perelle, S., Dilasser, F., Grout, J., and Fach, P. (2007). Screening food raw materials for the presence of the world's most frequent clinical cases of shiga toxinencoding Escherichia coli O26, O103, O111, O145 and O157. Int. J. Food Microbiol. 113, 284-288. doi: 10.1016/j.ijfoodmicro.2006.08.014 
Pintó, R. M., Costafreda, M. I., and Bosch, A. (2009). Risk assessment in shellfishborne outbreaks of Hepatitis A. Appl. Environ. Microbiol. 75, 7350-7355. doi: 10.1128/AEM.01177-09

Rodríguez, R. A., Pepper, I. L., and Gerba, C. P. (2009). Application of PCR-based methods to assess the infectivity of enteric viruses in environmental samples. Appl. Environ. Microbiol. 75, 297-307. doi: 10.1128/AEM.01150-08

Rodríguez-Lázaro, D., Cook, N., D’Agostino, M., and Hernandez, M. (2009). "Current challenges in molecular diagnostics in food microbiology," in Global Issues in Food Science and Technology, eds G. Barbosa-Cánovas, A. Mortimer, P. Colonna, D. Lineback, W. Spiess, and K. Buckle (Maryland Heights, MO: Elsevier), 211-223.

Rodríguez-Lázaro, D., Cook, N., Ruggeri, F. M., Sellwood, J., Nasser, A., Nascimento, M. S. J., et al. (2012). Virus hazards from food, water and other contaminated environments. FEMS Microbiol. Rev. 36, 786-814. doi: 10.1111/j. 1574-6976.2011.00306.x

Rodríguez-Lázaro, D., Lombard, B., Smith, H., Rzezutka, A., D’Agostino, M., Helmuth, R., et al. (2007). Trends in analytical methodology in food safety and quality: monitoring microorganisms and genetically modified organisms. Trends Food Sci. Technol. 18, 306-319. doi: 10.1016/j.tifs.2007.01.009
Sanchez, G., Elizaquível, P., and Aznar, R. (2012). Discrimination of infectious hepatitis A viruses by propidium monoazide real-time RT-PCR. Food Environ. Virol. 4, 21-25. doi: 10.1007/s12560-011-9074-5

Scallan, E., Hoekstra, R. M., Ângulo, F. J., Tauxe, R. V., Widdowson, M. A., Roy, S. L., et al. (2011). Foodborne illness acquired in the United States-major pathogens. Emerg. Infect. Dis. 17, 7-15. doi: 10.3201/eid1701. P11101

Conflict of Interest Statement: The authors declare that the research was conducted in the absence of any commercial or financial relationships that could be construed as a potential conflict of interest.

Copyright (c) 2016 Quijada, Fongaro, Barardi, Hernández and Rodríguez-Lázaro. This is an open-access article distributed under the terms of the Creative Commons Attribution License (CC BY). The use, distribution or reproduction in other forums is permitted, provided the original author(s) or licensor are credited and that the original publication in this journal is cited, in accordance with accepted academic practice. No use, distribution or reproduction is permitted which does not comply with these terms. 